\title{
ASOSIASI ANTARA INDEKS MASSA TUBUH, KEBUGARAN TUBUH BAGIAN ATAS DAN DAYA TAHAN RESPIRASI DI KALANGAN REMAJA
}

\author{
${ }^{1}$ Muhammad E. M. Simbolon \\ ${ }^{2}$ Dzihan Khilmi Ayu Firdausi \\ Correspondence: STKIP Muhammadiyah Bangka Belitung, \\ Bangka Belitung, Indonesia \\ E-mail: dyansimbolonpor@gmail.com, dzihanayu@gmail.com
}

\begin{abstract}
Abstrak
Penelitian ini bertujuan untuk menguji hubungan antara Indeks Massa Tubuh (IMT), kebugaran tubuh bagian atas, dan daya tahan respirasi remaja Kepulauan Bangka Belitung dengan rata-rata usia 18 tahun. Data dari 105 remaja dipilih secara acak dari remaja lulusan Sekolah Menengah Atas (SMA) yang mengikuti tes fisik pada ujian masuk prodi PJKR STKIP Muhammadiyah Bangka Belitung. Variabel yang diukur adalah tinggi badan, massa tubuh, kinerja push-up 60 detik (daya tahan otot lengan), sit-up 60 detik (daya tahan otot perut), dan lari jarak 1000-1200 meter (daya tahan respirasi). Berdasarkan hasil analiis data penelitian ini mengungkapkan bahwa indeks massa tubuh dan daya tahan respirasi memiliki korelasi yang signifikan dengan kekuatan dan daya tahan otot lengan ( $\left.t_{\text {hitung }}=3.79>t_{\text {tabel }}=1.66, t_{\text {hitung }}=2.51>t_{\text {tabel }}=1.66\right)$. Namun demikian, indeks massa tubuh dan daya tahan respirasi tidak memiliki korelasi yang signifikan dengan kekuatan dan daya tahan otot perut $\left(t_{\text {hitung }}=0.92>t_{\text {tabel }}=1.66, t_{\text {hitung }}=0.30>t_{\text {tabel }}=1.66\right)$.
\end{abstract}

\section{Kata Kunci: Indeks Massa Tubuh (IMT)}

\section{Pendahuluan}

Prevalensi kegemukan dan obesitas meningkat pada tingkat yang mengkhawatirkan. Obesitas terkait dengan sejumlah faktor risiko fisiologis dan prilaku (Bonora et al., 1983: 335). Hasil penelitian Hunt et al., (2011: 280) menunjukkan bahwa anak-anak dengan kadar lemak tubuh yang tinggi memiliki daya tahan respirasi yang rendah. Huang and Malina, (2010: 407) mengungkapkan pada hasil penelitian mereka bahwa indeks massa tubuh memiliki hubungan yang kuat dengan power tungkai anak-anak dan remaja, serta memiliki efek negatif pada power tungkai anak-anak dan remaja dengan kategori kegemukan dan obesitas. Studi terdahulu yang dilakukan oleh Sadhan, Koley, and Sandhu, (2007: 217) mengemukakan bahwa berdasarkan analisis regresi linier menunjukkan persentase lemak dan massa lemak memiliki korelasi kuat dengan $\mathrm{VO}_{2}$ max pada anak laki-laki. Studi lainnya mengungkapkan bahwa tidak ada perbedaan yang signifikan pada daya tahan respirasi antara laki-laki dan perempuan (Ramsbottom, Currie, and Gilder, 2010: 843).

Fungsi tubuh (skeletomuscular, cardiorespiratory, hematocirculatory, psychoneurological and endocrine-metabolic) terlibat dalam kinerja aktivitas fisik sehari-hari dan / atau latihan fisik (Ortega et al., 2008:1). Selain itu, latihan fisik juga penting sehubungan dengan kesehatan otak, secara khusus peningkatan volume latihan mengurangi demansia pada pria usia lanjut (Abbott et al., 2004: 1451) dan mempertahankan kinerja kognitif pada wanita usia lanjut (Wauve et al., 
2004:1459). Sekolah merupakan tempat yang tepat untuk program promosi kesehatan, bukti saat ini menunjukkan bahwa intervensi berbasis sekolah paling efektif untuk meningkatkan aktivitas fisik remaja (Andrade et al., 2014: 2).

Perbedaan sistem pendidikan Indonesia dan studi terdahulu yang telang diungkapkan, serta geografis Indonesia khususnya Kepulauan Bangka Belitung, maka perlu diketahui bagaimana sekolah di Indonesia khususnya Kepulauan Bangka Belitung memberikan dampak bagi IMT remaja, kebugaran tubuh bagian atas dan juga daya tahan respirasinya. Penelitian ini mengungkapkan hubungan antara Indeks Massa Tubuh, kebugaran tubuh bagian atas dan daya tahan respirasi remaja Kepulauan Bangka Belitung dengan rata-rata usia 18 tahun.

\section{Metode}

Sampel

Sanpel penelitian merupakan remaja dengan usia 17-21 tahun. Sampel merupakan remaja lulusan SMA sederajat yang mengikuti tes fisik pada penerimaan mahasiswa baru Prodi Pendidikan Jasmani Kesehatan dan Rekreasi di STKIP Muhammadiyah Bangka Belitung pada tahun 2016-2017. Total sampel 105 orang remaja berpartisipasi dalam antropometri dan uji kinerja lari jarak menengah 1000 meter putri/ 1200 meter putra. Berdasarkan jenis kelamin sampel terdiri dari 90 orang remaja putra dan 15 orang remaja putri. Penelitian ini disetujui oleh Lembaga Penelitian dan Pengabdian pada Masyarakat STKIP Muhammadiyah Bangka Belitung, Prodi Pendidikan Jasmani Kesehatan dan Rekreasi STKIP Muhammadiyah Bangka Belitung, serta diketahui oleh Institusi STKIP Muhammadiyah Bangka Belitung, dan juga persetujuan tertulis dari sampel dan / atau orang tua / wali mereka.

\section{Indeks Massa Tubuh}

Indeks massa tubuh dihitung sebagai massa tubuh $(\mathrm{kg})$ dibagi tinggi tubuh kuadrat $\left(\mathrm{m}^{2}\right)$ dan kemudian peserta dikelompokkan kedalam kategori 'normal' ( $\leq 24.9$ $\mathrm{kg} / \mathrm{m}^{2}$, termasuk underweight), 'overweight' $\left(25.0-29.9 \mathrm{~kg} / \mathrm{m}^{2}\right)$, dan 'obesity' ( $\geq$ $30.0 \mathrm{~kg} / \mathrm{m}^{2}$ ) (Hoeger 2008: 119). Tinggi dan massa tubuh peserta diukur oleh mahasiswa senior yang terlatih dalam antropometri terkait penerimaan mahasiswa baru dan telah lulus mata kuliah evaluasi pembelajaran penjas. Peserta bertelanjang kaki dan berpakaian ringan selama antropometri. Tinggi dan massa tubuh sampel diukur menggunakan timbangan $(\mathrm{kg})$ dan meteran tinggi badan $(\mathrm{cm})$ yang telah dikalibrasi.

\section{Kebugaran Tubuh Bagian Atas}

Tes push up dan sit up dengan waktu selama 60 detik digunakan untuk mengukur daya tahan otot lengan dan otot perut (Widiastuti 2011: 45-46). Semua peserta diinstruksikan untuk melakukan gerakan push up dan sit up yang benar sebanyak mungkin dalam tempo waktu 60 detik. Jumlah gerakan yang benar dihitung dan dicatat. Berdasarkan hasil studi Nelson, Yoon, and Nelson, (1991: 441) menyatakan bahwa tes push up memiliki tingkat keefektifan dan reliabilitas yang signifikan dan dapat digunakan sebagai uji fungsional terhadap kekuatan dan daya tahan tubuh bagian atas untuk pria dan wanita usia sekolah sampai dewasa. 


\section{Daya Tahan Respirasi}

Tes lari/jalan digunakan untuk mengukur daya tahan respirasi peserta. Uji kinerja tes lapangan lari/jalan jarak menengah 1200 meter untuk putra dan 1000 meter untuk putri (Widiastuti 2011: 47). Semua peserta diinstruksikan untuk menyelesaikan tes secepat mungkin. Jika mereka tidak mampu berlari maka diizinkan berjalan. Waktu yang ditempuh peserta dicatat dalam menit dan detik menggunakan stopwatch yang telah dikalibrasi.

\section{Analisis Data}

Statistik deskriptif digunakan untuk memberikan gambaran karakteristik sampel dan variabel penelitian. Pearson's correlation digunakan untuk menguji hubungan antara indeks massa tubuh, kebugaran tubuh bagian atas dan daya tahan respirasi peserta. selanjutnya uji signifikansi menggunakan uji t. Taraf signifikansi yang digunakan 0.05 untuk semua analisis. Semua analisis statistik pada data penelitian ini dibantu dengan menggunakan Microsoft Excel 2013 untuk windows 7.

\section{Pembahasan}

Karakteristik dari sampel penelitian dapat dilihat pada tabel 1. Secara keseluruhan remaja putra memiliki berat dan tinggi tubuh yang lebih dibandingkan remaja putri. Namun demikian, baik remaja putra maupun putri memiliki indeks massa tubuh yang 'normal'. Performa daya tahan respirasi remaja putra lebih baik dibandingkan remaja putri. Performa kekuatan dan daya tahan otot lengan remaja putra dan putri memiliki rata-rata yang relatif sama. Perbedaan pada rata-rata performa kekuatan dan daya tahan otot perut remaja putra lebih baik dibandingkan remaja putri.

Tabel 1. Karakteristik dari sampel penelitian

\begin{tabular}{|c|c|c|c|c|c|}
\hline & \multicolumn{2}{|c|}{ Keseluruhan } & \multicolumn{2}{|c|}{ Putra } & Putri \\
\hline$N$ & & 105 & & 90 & 15 \\
\hline Usia (tahun) & 18.48 & \pm 1.57 & 18.64 & \pm 1.62 & $17.37 \pm 0.74$ \\
\hline Berat Tubuh $(k g)$ & 58.33 & \pm 11.21 & 59.12 & \pm 11.55 & $53.60 \pm 8.10$ \\
\hline Tinggi Tubuh $(m)$ & 1.64 & \pm 0.07 & 1.65 & \pm 0.06 & $1.56 \pm 0.04$ \\
\hline Indeks Massa Tubuh $\left(\mathrm{kg} / \mathrm{m}^{2}\right)$ & 21.61 & \pm 3.60 & 21.53 & \pm 3.59 & $22.06 \pm 3.78$ \\
\hline Push-up (jumlah gerakan/ menit) & 29.84 & \pm 9.15 & 29.86 & \pm 9.29 & $29.73 \pm 8.50$ \\
\hline Sit-up (jumlah gerakan/ menit) & 32.62 & \pm 8.70 & 34.51 & \pm 7.49 & $21.27 \pm 6.70$ \\
\hline Daya Tahan Respirasi (Menit-detik) & 6.51 & \pm 1.04 & 6.44 & \pm 1.05 & $6.91 \pm 0.90$ \\
\hline
\end{tabular}

Nilai merupakan mean $\pm S D$

Tabel 2 menunjukkan hubungan antar tiap-tiap variabel. Berat tubuh memiliki korelasi yang kuat dengan indeks massa tubuh $(r=0.891)$. Tinggi tubuh berkorelasi relatif kecil dengan indeks massa tubuh $(r=0.036)$. Kekuatan dan daya tahan otot lengan berkorelasi sedang dengan indeks massa tubuh $(r=-$ 0.350). Kekuatan dan daya tahan otot perut berkorelasi relatif kecil dengan indeks 
massa tubuh $(r=-0.094)$. Daya tahan respirasi memiliki korelasi yang relatif kecil dengan indeks massa tubuh $(r=0.027)$.

Tabel 2. Hubungan antara indeks massa tubuh dan daya tahan respirasi remaja

\begin{tabular}{lccccc}
\hline & $\begin{array}{c}\text { Berat } \\
\text { Tubuh }\end{array}$ & $\begin{array}{c}\text { Tinggi } \\
\text { Tubuh }\end{array}$ & Push-up & Sit-up & $\begin{array}{c}\text { Daya Tahan } \\
\text { Respirasi }\end{array}$ \\
\hline Indeks Massa Tubuh & 0.891 & 0.036 & $\mathbf{- 0 . 3 5 0}$ & $\mathbf{- 0 . 0 9 4}$ & $\mathbf{0 . 0 2 7}$ \\
Berat Tubuh & - & 0.476 & -0.377 & 0.017 & -0.018 \\
Tinggi Tubuh & & - & -0.121 & 0.248 & -0.086 \\
Push-up & & & - & 0.032 & $\mathbf{0 . 0 3 2}$ \\
Sit-up & & & & - & $\mathbf{- 0 . 2 3 8}$ \\
Daya Tahan Respirasi & & & & & - \\
\hline
\end{tabular}

Tinggi tubuh memiliki korelasi yang sedang dengan berat tubuh $(r=$ 0.476). Daya tahan otot lengan berkorelasi sedang dengan berat tubuh dan berkorelasi kecil dengan tinggi tubuh $(r=-0.377, r=-0.121)$. Daya tahan otot perut berkorelasi kecil dengan berat, tinggi tubuh, dan juga daya tahan otot lengan $(r=0.017, r=0.248, r=0.032)$. Daya tahan respirasi berkorelasi relatif kecil dengan berat tubuh, tinggi tubuh, daya tahan otot lengan, dan juga daya tahan otot perut $(r=-0.018, r=-0.086, r=0.032, r=-0.238)$.

Tabel 3. Hasil uji signifikansi korelasi

\begin{tabular}{|c|c|c|}
\hline & Indeks Massa Tubuh & Daya Tahan Respirasi \\
\hline Push-up & 3.79 & 2.51 \\
\hline Sit-up & 0.92 & 0.30 \\
\hline Daya Tahan Respirasi & 0.30 & - \\
\hline
\end{tabular}

Berdasarkan hasil uji signifikansi korelasi sebagaimana yang disajikan pada tabel 3. Indeks massa tubuh dan daya tahan respirasi memiliki korelasi yang signifikan dengan kekuatan dan daya tahan otot lengan $\left(t_{\text {hitung }}=3.79>t_{\text {tabel }}=1.66\right.$, $\left.t_{\text {hitung }}=2.51>\mathrm{t}_{\text {tabel }}=1.66\right)$. Hal yang serupa telah teridentifikasi pada penelitian Liao et al. (2013: 1801) bahwa kekuatan dan daya ledak tubuh bagian bawah memiliki korelasi yang tinggi dengan indeks massa tubuh remaja di Taiwan. Sedangkan indeks massa tubuh dan daya tahan respirasi tidak memiliki korelasi yang signifikan dengna kekuatan dan daya tahan otot perut ( $\mathrm{t}_{\text {hitung }}=0.92>\mathrm{t}_{\text {tabel }}=$ 1.66 , $\mathrm{t}_{\text {hitung }}=0.30>\mathrm{t}_{\text {tabel }}=1.66$ ). Indeks massa tubuh dan daya tahan respirasi tidak memiliki korelasi yang signifikan $\left(\left(t_{\text {hitung }}=0.30>t_{\text {tabel }}=1.66\right)\right.$. Kebugaran otot dan daya tahan respirasi secara signifikan dan negatif berkorelasi dengan resiko kardiometabolik, terpisah satu sama lain (Buchan et al., 2015: 10).

Temuan pada penelitian Chen, Housner, and Gao, (2017: 1) menyoroti pentingnya menjaga indeks massa tubuh normal selama tahun-tahun sekolah dasar guna mencapai dan menjaga kebugaran fisik yang lebih baik. Remaja dengan keterlibatan tinggi dalam aktivitas fisik menunjukkan indeks massa tubuh dan komposisi tubuh yang proposional dan tingkat kebugaran kardiorespirasi yang lebih baik (Ahmed et al., 2017: 10). Berdasarkan hasil penelitian ini ditemukan bahwa indeks massa tubuh dan daya tahan kardiorespirasi hanya berkorelasi dengan kekuatan dan daya tahan otot lengan. Berat badan, tinggi badan, jenis 
kelamin, dan indeks massa tubuh adalah pradiktor daya tahan respirasi yang baik di kalangan siswa sekolah (Olawale et al. 2017: 70). Penting bagi kita untuk menyiapkan program yang dapat memberikan intervensi positif terhadap indeks massa tubuh, kebugaran tubuh bagian atas, dan juga daya tahan respirasi remaja.

\section{Simpulan}

Penelitian ini dapat bermanfaat untuk membuat program pola hidup sehat pada remaja. Khususnya pendidikan jasmani di sekolah yang merupakan pusatnya pendidikan pada kalangan remaja. Pendidikan jasmani dapat dijadikan instrument untuk mempromosikan dan juga melatih kalangan remaja untuk dapat memiliki pola hidup sehat.

\section{Rujukan}

Abbott, R. D., White, L. R., Ross, G. W. Masaki, K. H, Curb, J. D., \& Petrovich, $\mathrm{H}, 2004$. Walking and dementia in physically capable elderlymen. Journal of the American Medical Association, 292, 1447-1453.

Ahmed, Md Dilsad et al, 2017. "The Self-Esteem, Goal Orientation, and HealthRelated Physical Fitness of Active and Inactive Adolescent Students." Cogent Psychology 4(1): 1-14. http://doi.org/10.1080/23311908.2017.1331602.

Andrade, Susana et al, 2014. "A School-Based Intervention Improves Physical Fitness in Ecuadorian Adolescents: A Cluster-Randomized Controlled Trial.” International Journal of Behavioral Nutrition and Physical Activity 11(1): 1-17.

Buchan, Duncan S. et al, 2015. "Relationships between Cardiorespiratory and Muscular Fitness with Cardiometabolic Risk in Adolescents." Research in Sports Medicine 23(3): 227-39.

Chen, Han, Lynn Housner, and Yong Gao, 2017. "The Influence of Weight Change on Physical Fitness from Childhood to Adolescence." Measurement in Physical Education and Exercise Science 21(3): 113-20. http://dx.doi.org/10.1080/1091367X.2016.1262379.

Hoeger, Wernew W.K, 2008. Principles and Labs for Physical Fitness. 6th ed. USA: Thomson Wadsworth.

Huang, Yi Ching, and Robert M. Malina, 2010. "Body Mass Index and Individual Physical Fitness Tests in Taiwanese Youth Aged 918 Years." International Journal of Pediatric Obesity 5(5): 404-11.

Hunt, Linda P. et al, 2011. "Blood Pressure in Children in Relation to Relative Body Fat Composition and Cardio-Respiratory Fitness." International Journal of Pediatric Obesity 6(3-4): 275-84. http://informahealthcare.com/doi/abs/10.3109/17477166.2011.583655.

Liao, Yung et al, 2013. "Associations between Health-Related Physical Fitness and Obesity in Taiwanese Youth." Journal of Sports Sciences 31(16): 17971804.

Nelson, J K, S H Yoon, and K R Nelson, 1991. "A Field Test for Upper Body Strength and Endurance." Research quarterly for exercise and sport 62(4): 436-41. http://www.ncbi.nlm.nih.gov/pubmed/1780568. 
Olawale, Onagbiye S., Mulubwa Mwila, Young M.E. Marie, and Toriola A. Lamina, 2017. "Relationship between Cardiorespiratory Fitness and Anthropometric Variables among School-Going Adolescents in Nigeria." The Anthropologist 29(1): 65-72. https://www.tandfonline.com/doi/full/10.1080/09720073.2017.1351514.

Ortega, F. B., J. R. Ruiz, M. J. Castillo, and M. Sjöström, 2008. "Physical Fitness in Childhood and Adolescence: A Powerful Marker of Health." International Journal of Obesity 32(1): 1-11.

Ramsbottom, R., J. Currie, and M. Gilder, 2010. "Relationships between Components of Physical Activity, Cardiorespiratory Fitness, Cardiac Autonomic Health, and Brain-Derived Neurotrophic Factor." Journal of Sports Sciences 28(8): 843-49.

Sadhan, Berry, Shyamal Koley, and Jaspal Singh Sandhu, 2007. "Relationship Between Cardiorespiratory Fitness, Body Composition and Blood Pressure in Punjabi Collegiate Population." Journal of Human Ecology 22(3): 21519.

Widiastuti, 2011. Tes Dan Pengukuran Olahraga. Jakarta: Bumi Timur Jaya. 